\title{
CARBON NANOSTRUCTURES GROWN ON Fe-Cr-Al ALLOY
}

\author{
Mária Čaplovičová ${ }^{*}$ L’ubomír Čaplovič ${ }^{* *}$ - Dalibor Búc ${ }^{* * *}$ \\ — Peter Vinduška ${ }^{* * *}$ — Ján Janík ${ }^{* * *}$
}

\begin{abstract}
The morphology and nanostructure of carbon nanotubes (CNTs), synthesized directly on Fe-Cr-Al-based alloy substrate using an alcohol catalytic chemical vapour deposition method (ACCVD), were examined by transmission electron microscopy (TEM). The grown CNTs were entangled with chain-like, bamboo-like, and necklace-like morphologies. The CNT morphology was affected by the elemental composition of catalysts and local instability of deposition process. Straight and bended CNTs with bamboo-like nanostructure grew mainly on $\gamma$-Fe and $\mathrm{Fe}_{3} \mathrm{C}$ particles. The synthesis of necklace-like nanostructures was influenced by silicon oxide, and growth of chain-like nanostructures was supported by a catalysts consisting of $\mathrm{Fe}$, Si, oxygen and trace of $\mathrm{Cr}$. Most of nanotubes grew according to base growth mechanism.
\end{abstract}

K e y w o r ds: carbon nanotubes, alcohol catalytic chemical vapor deposition, transmission electron spectroscopy

\section{INTRODUCTION}

Carbon nanotubes (CNTs) are widely studied because of their striking mechanical, physical, electronic and chemical properties $[1,2]$. CNTs predominantly have been synthesized by arc-vaporization [3], laser ablation [4] and thermal chemical vapor deposition (CVD) [5]. The CVD methodology has been based on a two-step procedure that involves the deposition of a catalyst and subsequent growth of CTNs.

The synthesis of nanostructures on bulk metallic substrates such as stainless steels [6-8], NiCr-based alloys [9], and some pure metals, eg, nickels [10] and Mo [11], is possible without any pre-treatment. However, for controlling the growth of CNTs onto metallic substrates, their surfaces are modified by oxidation, reduction $[9,12,13]$ or etching using suitable etchants $[14,15]$. The growth of CNTs directly on the surfaces of conducting metallic substrates is attractive because it solves the adhesion problem of CNTs to the substrate and satisfies the condition of electric conductivity at some electric and electronic applications [10]. CNTs grown on metallic substrates can be used as electrodes, for instance, for lithium batteries [10], electric double-layered capacitors (EDLC) [15] and emitters in luminescent mercury-free tubes $[9,16]$.

In this study, the CNTs, synthesized by an ACCVD method on Fe-Cr-Al-based alloy substrate are investigated by TEM. Nanostructures are examined on the base of their morphology, internal structure and graphitic structure. The self-catalytic effect of the substrate, growth mechanism of nanotubes and effect of surface finishing on the growth of CNTs are highlighted.

\section{EXPERIMENTAL}

The carbon deposit was directly prepared on wires made of Fe-Cr-Al based alloy (trademark Kanthal A1) by an alcohol catalytic CVD (ACCVD) method. The chemical composition on the surface of the $\mathrm{Fe}-\mathrm{Cr}-\mathrm{Al}$ substrate before the deposition obtained by EDS analysis was as follows: Fe $69.12 \mathrm{wt} \%, \mathrm{Cr} 22.48 \mathrm{wt} \%, \mathrm{Al} 7.14 \mathrm{wt} \%$, Si $0.48 \mathrm{wt} \%, \mathrm{C} 0.78 \mathrm{wt} \%$. The wire diameter was $0.7 \mathrm{~mm}$. The substrates were not pretreated prior to deposition except cleaning by ultrasonic agitation in acetone and drying at ambient temperature. The carbonaceous deposit was fabricated on the wire surfaces by pyrolytic decomposition of ethanol $\left(\mathrm{C}_{2} \mathrm{H}_{5} \mathrm{OH}\right)$ with purity of $99.9 \%$ at $2500 \mathrm{~Pa}$. The furnace temperature was kept at $700^{\circ} \mathrm{C}$ for $60 \mathrm{~min}$. No additional heat treatment of the sample was used. More detailed information on the deposition process is reported elsewhere [17].

TEM samples were prepared by a positive replica (twostage replication) technique [18]. Since produced CNTs created thick layer on the substrate and in order to estimate the relationship between the nanotube growth density, substrate surface roughness and catalyst diameter, the plastic replication was carried out in two stages. In the first stage, the density of CNTs was depleted by the first replica extraction, and in the second stage, the depleted CNTs were then used for sampling.

The study of the carbon nanotubes was performed using transmission electron microscopes JEOL 2000 FX and JEOL 200CX, working at accelerating voltages of 160 and $200 \mathrm{kV}$, respectively. The identification of the catalyst particles and the assessment of crystallinity of nanotubes were conducted by the energy dispersive $\mathrm{x}$-ray

\footnotetext{
* Department of Geology of Mineral Deposits, Comenius University, Mlynská dolina, 84215 Bratislava, Slovakia, ** Department of Materials Engineering, Faculty of Materials Science and Technology, Slovak University of Technology, Bottova 23, 917 24 Trnava, Slovakia, *** Department of Microelectronics, Faculty of Electrical Engineering and Information Technology, Slovak University of Technology, Ilkovičova 3, 81219 Bratislava, Slovakia, dalibor.buc@stuba.sk
} 

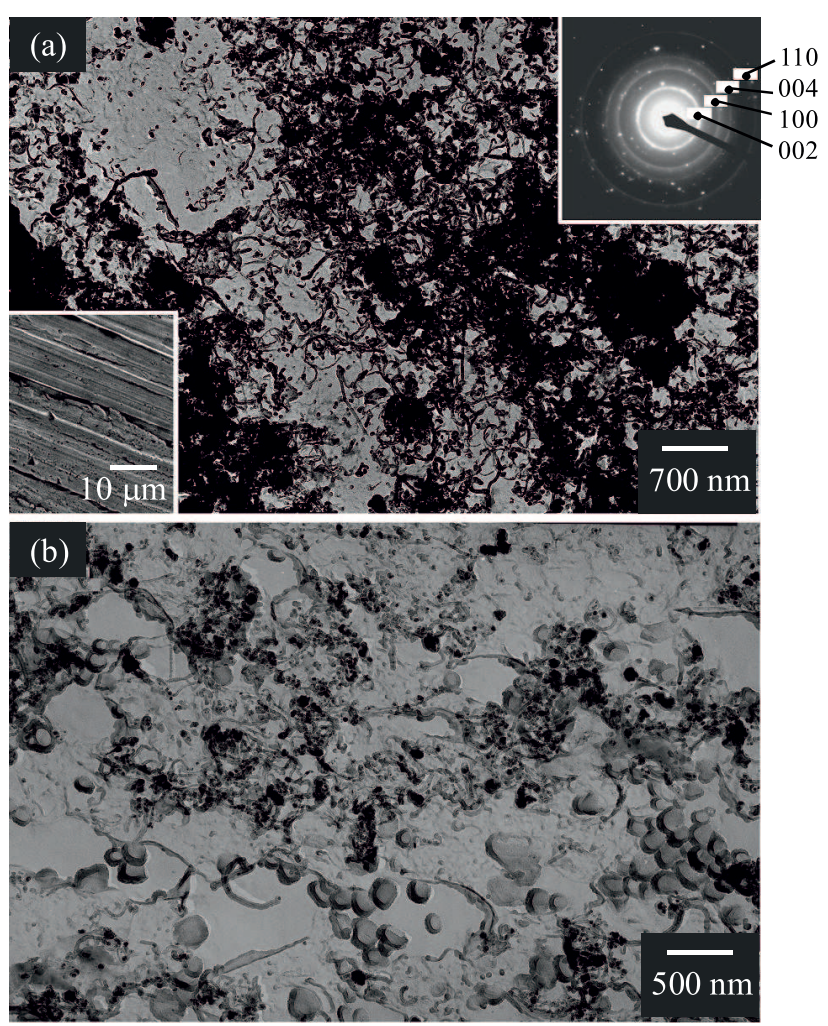

Fig. 1. Low magnification TEM image of nanostructures grown predominantly (a) along the deformation lines, (b) in the areas with tiny nanoparticles. Surface roughness of the substrate before deposition (scratches induced by the mechanical treatment of the wire prior to oxidation and dimples after extraction of particles) is

evident in left inset. Relevant SAED pattern is in right inset

spectroscopy (EDS) and selected area electron diffraction (SAED), and HRTEM methods, respectively. The EDS analysis was performed using a LINK detector with AN 10000 system integrated with the TEM. A scanning electron microscope (SEM) JEOL JXA 840A was employed to examine the surface morphology of the substrate prior to the deposition.

\section{RESULTS AND DISCUSSION}

Pyrolytical decomposition of ethanol led to the combustion with high density of CNTs on non-pretreated surfaces of Khantal $A 1$ as evidenced in low magnification TEM images, Fig. 1(a,b). Figure 2 displays a more detailed bright-field TEM image of a representative carbon deposit.

The as-grown deposit consists of non-aligned CNTs spread non-uniformly on the substrate (Fig. 1(a)). It was found by TEM that CNT distribution is markedly affected both by the surface roughness (right bottom inset in Fig. 1(a)) and by the size of particles, Fig. 1(b). As can be seen from Fig. 1(a,b), CNTs were predominantly located at the surface asperities and in the regions containing the fine nanoparticles. Consequently, it is proposed that both particles having the size up to $100 \mathrm{~nm}$ and sur- face asperities acted as active catalysts suitable for CNT synthesis in this case. Since there were registered $\mathrm{Fe}, \mathrm{Al}$, $\mathrm{Cr}, \mathrm{Si}, \mathrm{C}$ and oxygen as majority elements and $\mathrm{Mg}, \mathrm{S}$, $\mathrm{P}, \mathrm{Si}, \mathrm{K}$ and $\mathrm{Ca}$ as a trace elements in EDS spectra collected from clusters of nanoparticles and CNTs, it is reasonable to suppose that these elements can catalytically affect the nanotube growth and their final morphology. Good crystallinity of the grown nanotubes is evidenced both by sharp concentric diffraction rings in the SAED pattern (upper inset in Fig. 1(a)) being recorded from a bunch of CNTs, and also by HRTEM image depicting the detail of CNT wall, Fig. 3.

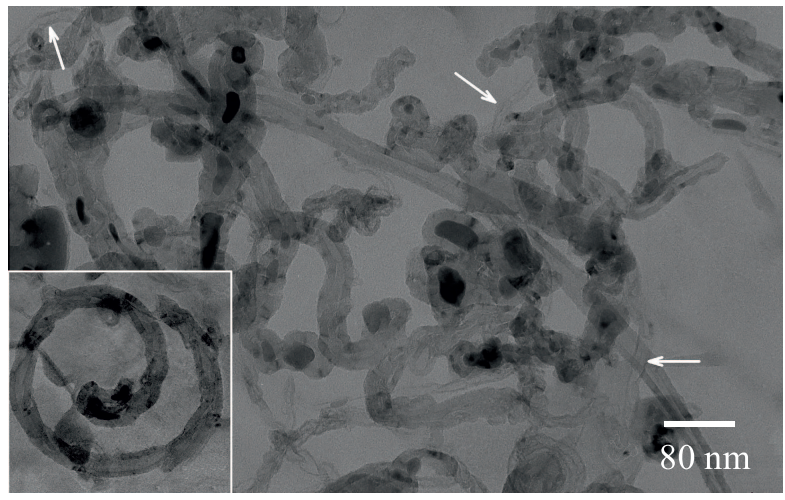

Fig. 2. More detailed TEM image of CNT entanglement. The inset shows plane spiral morphology of CNT. The CNTs with thin walls and large hollow core are indicated with arrows

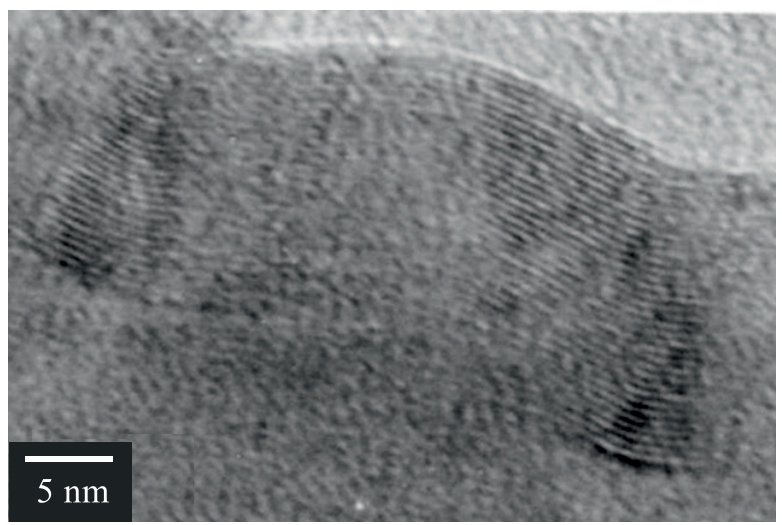

Fig. 3. HRTEM image of wavy CNT wall created by 33 layers. The interlayer spacing is $0.34 \mathrm{~nm}$

As-grown nanotubes are entangled, curled, bent, and many of them confine straight segments with constant diameters, continuous tube walls and bamboo-like structure. The plane-spiral morphology of CNTs, inset of Fig. 2, are abundant. The crooked and plane-spiral nanotubes mostly emerge with chain-like structure. Many grown nanotubes are multi-structural with straight tubular, bamboo-like, and chain-like segments of different lengths within a single CNT. The majority of synthesized CNTs grow with outer diameters ranging from 20 to $50 \mathrm{~nm}$ and hollow cores approaching to one third of 

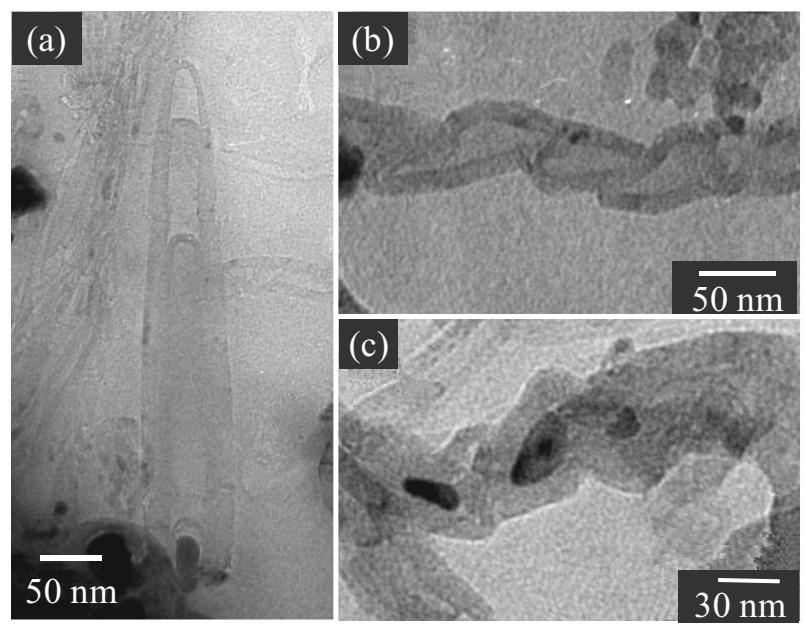

Fig. 4. TEM image of (a) - bamboo-like, (b) and (c) - chain-like structures of MWCNTs

the whole tube diameter. However, nanotubes with outer diameter of 10 to $15 \mathrm{~nm}$ and wall thickness of $\sim 2 \mathrm{~nm}$ are also observed in the soot as indicated by arrows in Fig. 2.

It is typical for bamboo-like CNTs the formation of compartments in the hollow core. The morphology of an entire nanotube which has a bamboo-like structure is determined by the outer graphitic layers of the walls, rather than by those layers which are nearer to the centre of the nanotube, because the outermost graphene sheets are continual along the tube axis $[19,20]$. Example of CNT bamboo-like structure, which was very often observed in as-grown carbon deposit, is shown in Fig. 4(a). As it can be seen from this image, the individual compartments are separated by the thin diapraghms of carbon.

Chain-like nanotubes are made of hollow carbon cages or carbon cages confining catalytic particles that are interconnected as follows: the open end of one cage is coupled with the dome of another one, Fig. 4(b,c). These building units usually exhibit various shapes in the chains. Mostly they possess elliptical, knot-like and even irregular heart-like TEM projection, whereby the hollow core of individual segments is frequently divided by internal diaphragms characteristic for bamboo-like CNTs.

It was found that the nanoparticles supporting the growth of the straight, coiled, and curved CNTs consist mainly of $\mathrm{Fe}$ or $\mathrm{Fe}$ with a trace amount of $\mathrm{Cr}$, inset of Fig. 5(a). The evolution of thin-walled carbon nanotubes such as arrowed in Fig. 2 is induced by $\mathrm{SiO}_{2} / \mathrm{Fe}$ catalyst, as was determined by EDS method.

Elongated, quasi-spherical and droplet-like Fe-catalyst shapes were found to be most widespread captured in these CNTs. Fe-particles with fluctuating diameter were also registered, Fig. 5(c). According to [21] the fluctuating diameter of nanowires inside the CNTs could be the result of fluidity of catalyst particles during the nanotube synthesis. The morphology of the nanowires encapsulated in CNTs in Fig5(c) and 5(d) confirms this. It was found that several CNTs were filled with nanowires with the length more than $150 \mathrm{~nm}$. The Fe catalysts confined in the core of CNTs are mostly $\gamma$-Fe crystallizing in a facecentered-cubic (FCC) structure with a space group Fm$3 \mathrm{~m}$ as the analysis of CBED pattern indicates, Fig. $5(\mathrm{~b})$. In addition to $\gamma$-Fe, $\mathrm{Fe}_{3} \mathrm{C}$ was identified enclosed in nanotubes as well. However, no $\alpha$-Fe inside the investigated
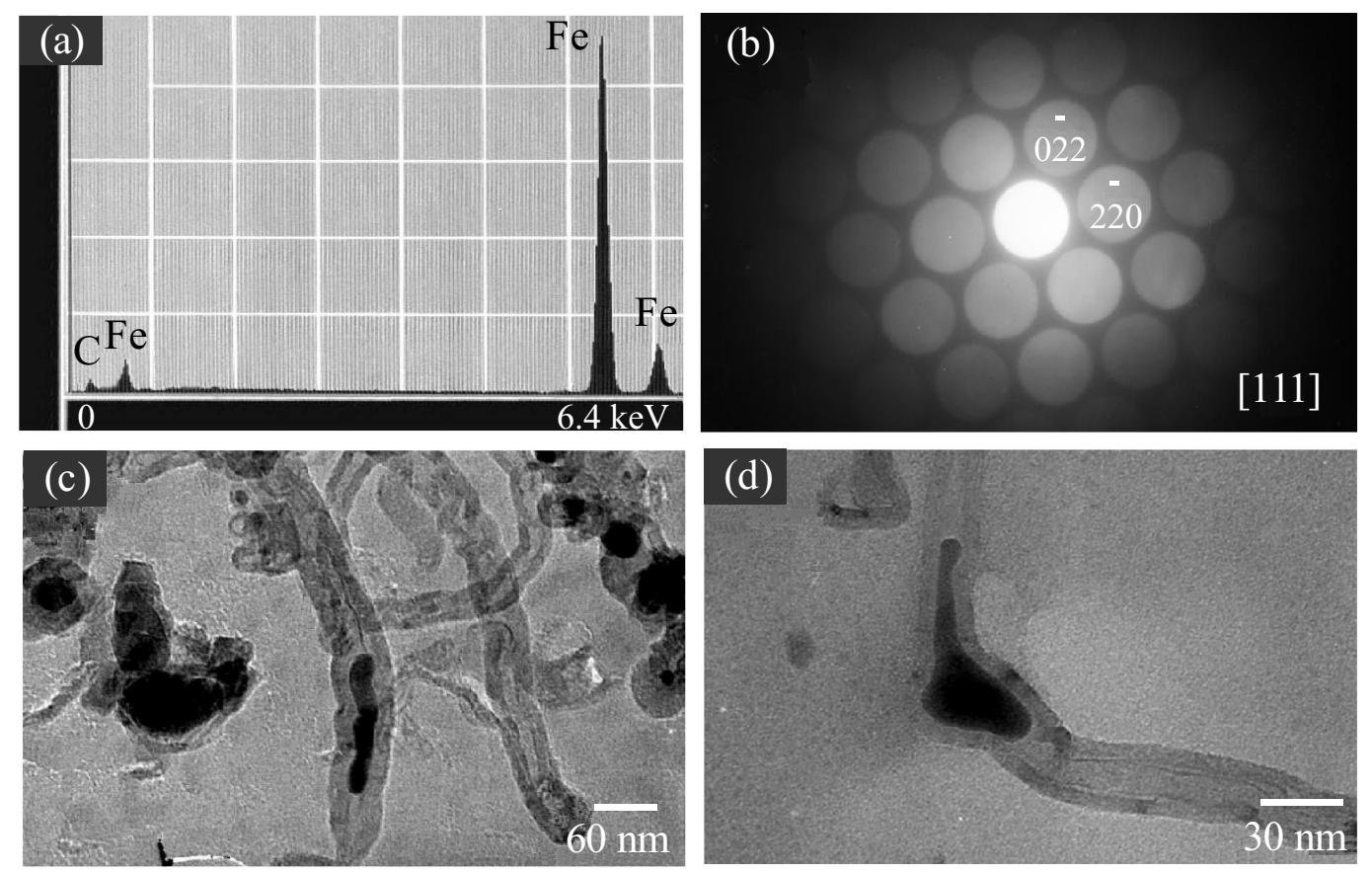

Fig. 5. (a) - EDS spectrum and, (b) - CBED pattern of nanoparticle encapsulated in CNT consisting of $\gamma$-Fe with FCC structure. Various morphologies of catalysts embedded inside the nanotubes are depicted in (c) and (d). 
CNTs was detected. The retention of high temperature modification $\gamma$-Fe enclosed inside the CNTs at low temperatures was previously reported $[22,23]$. Likely pressure confinement effect $(\sim 1.5 \mathrm{GPa})$ prevents this phase conversion because the $\gamma$-Fe to $\alpha$-Fe transformation involves the volume increase by $9 \%[22]$.

Growing most abundant CNTs with a chain-like structure, as depicted in Fig. 4(b,c), may be supported by $\mathrm{Fe}_{2} \mathrm{O}_{3} / \mathrm{SiO}_{2}$ or $\mathrm{Fe}_{2} \mathrm{O}_{3} / \mathrm{Al}_{2} \mathrm{O}_{3}$ catalyst systems as was previously shown $[24,25]$. Since EDS chemical analyses recorded from nanoparticles catalyzing the growth of chain-like CNTs revealed mostly the presence of $\mathrm{Fe}, \mathrm{Si}$, oxygen and trace of $\mathrm{Cr}$, it is reasonable presume that the final nanostructure of chain-like CNTs results from the collective effect of these elements.

The "necklace-like" morphology [24] of fibrous carbon with a thin hollow core was found in the deposit as well, Fig. 6. The outer diameter of nano-necklaces quasiperiodically varies from 59 to $106 \mathrm{~nm}$. However, the hollow diameter is almost invariable along the entire nanofibrils. EDS analysis in inset of Fig. 6 reveals that the "nanonecklaces" predominantly grow in the regions with relatively high content of Si and oxygen.

The growth mechanism of nanotubes was determined based on the distribution of catalyst particles inside the CNTs. The base growth mechanism prevailed in our sample as the dominant occurrence of catalyst particles was found out at the most of the CNT roots, in the meantime most of the CNT growth fronts were free of metal nanoparticles. Base growth of the randomly selected MWCNT is exemplified in Fig. 4(a). During the CNT growth, elementary processes of adsorption and dissolving carbon precursor in catalyst, its diffusion and then precipitation of graphite layers at the colder zone of the particles [12] has occurred.

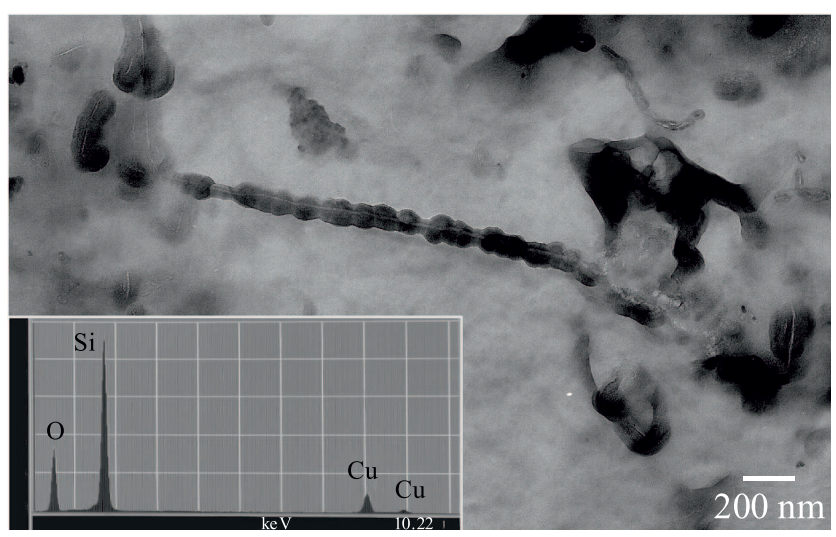

Fig. 6. Representative TEM image of a "necklace-like" CNT with a quasi-periodical variation of external diameters. EDS spectrum collected from the area with abundant "necklace-like" structure indicates the presence of $\mathrm{Si}$ and oxygen

\section{CONCLUSIONS}

Different carbon nanostructures were prepared on a Fe-Cr-Al alloy by an ACCVD method. The surface of the
Fe-Cr-Al wire served as a substrate and a catalyst source. Since the substrate surface was non-uniformed in chemical composition and morphology on micro-scale, morphologically different nanostructures and their uneven distribution over the substrate evolved at pyrolytic decomposition of ethanol vapours.

The morphology of CNTs alters not only with the chemical nature of catalyst nanoparticles, but also with the local instability of deposition process. Based on EDS analyses recorded from catalyst particles it was concluded that most CNTs were catalyzed by nanoparticles consisting of $\mathrm{Fe}, \mathrm{Si}$, oxygen and trace $\mathrm{Cr}$, but many of them grew with assistance of $\gamma$-Fe and $\mathrm{Fe}_{3} \mathrm{C}$ catalysts as well. "Nano-necklace" structures are grown in domains with high content of $\mathrm{SiO}_{2}$. The influence of $\mathrm{Al}$ and trace elements found on the surface of the substrate on the synthesis of nanostructures was not noted.

All the investigated nanotubes are multiwalled structures. The straight, curved, curled and plane spiral MWCNTs usually exhibit chain-like structure. Their common morphological feature is undulation on the outer CNT surface.

\section{Acknowledgements}

This project has been financially supported by the Slovak Ministry of Education VEGA grants No. 1/0337/08, $1 / 0807 / 08,1 / 0553 / 09$, APVV 0548-07. Contribution is realized with the support of the project "Centre for Development and Application of Advanced Diagnostic Methods in Processing of Metallic and Nonmetallic Materials," ITMS: 26220120014, OP Research and development (implementation of project activities 05/2009 - 04/2011).

\section{REFERENCES}

[1] IIJIMA, S. : Helical Microtubules of Graphitic Carbon, Nature 354 (1991), 56-58.

[2] SAITO, R.-DRESSELHAUS, G.-DRESSELHAUS, M. S. : Physical Properties of Carbon Nanotubes, Imperial College press, London.

[3] ZENG, H.-ZHU, L.-HAO, G.-SHENG, R.: Synthesis of Various Forms of Carbon Nanotubes by AC Arc Discharge, Carbon 36 No. 3 (1998), 259-261.

[4] GUO, T.-NIKOLAEV, P.-THESS, A.-COLBERT, D. T.SMALLEY, R. E.: Catalytic Growth of Single-Walled Nanotubes by Laser Vaporization, Chem Phys Lett 243 (1995), 49-54.

[5] PRADHAN, D.-SHARON, M. : Carbon Nanotubes, Nanofilaments and Nanobeads by Thermal Chemical Vapor Deposition Process, Mat Sci Eng B 96 No. 1 (2002), 24-28.

[6] LIN, C.-L.-CHEN, C.-F.-SHI, S.-C.: Field Emission Properties of Aligned Carbon Nanotubes Grown on Stainless Steel using CH4/CO2 Reactant Gas, Diamond Relat Mater 13 No. 4-8 (2004), 1026-1031.

[7] YUAN, L.-SAITO, K.-HU, W.-CHEN, Z. : Ethylene Flame Synthesis of Well-Aligned Multi-Walled Carbon Nanotubes, Chem Phys Lett 346 No. 1-2 (2001), 23-28.

[8] RANDALL, L.-WAL, V.-HALL, L. J.: Carbon Nanotube Synthesis Upon Stainless Steel Meshes, Carbon 41 No. 4 (2003), 659-672. 
[9] NOURY, O.-STÖCKLI, T.-CROCI, M.-CHÂTELAIN, A. -BONARD, J. M.: Growth of Carbon Nanotubes on Cylindrical Wires by Thermal Chemical Vapor Deposition, Chem Phys Lett 346 No. 5-6 (2001), 349-355.

[10] DU, C.-PAN, N. : CVD Growth of Carbon Nanotubes Directly on Nickel Substrate, Mat Lett 59 No. 13 (2005), 1678-1682.

[11] KOWALSKA, E.-CZERWOSZ, E.-DLUZEWSKI, P. A.KOZLOWSKI, M.-RADOMSKA, J. : Electron Emissive Properties of CNT Films Grown by Catalytic Method on Different Types of Substrates, Diamond Relat Mater 13 No. 4-8 (2004), 1008-1101.

[12] YUAN, L.-LI, T.-SAITO, K. : Growth Mechanism of Carbon Nanotubes in Methane Diffusion Flames, Carbon 41 No. 10 (2003), 1889-1896.

[13] DEEPAK, F. L.-JOHN, N. S.-GOVINDARAJ, A.-KULKARNI, G. U.-RAO, C. N. R. : Nature and Electronic Properties of Y-Junctions in CNTs and N-Doped CNTs Obtained by the Pyrolysis of Organometallic Precursors, Chem Phys Lett 411 No. 4-6 (2005), 468-473.

[14] PAN, C.-LIU, Y.-CAO, F.-WANG, J.-REN, Y.: Synthesis and Growth Mechanism of Carbon Nanotubes and Nanofibers from Ethanol Flames, Micron 35 No. 6 (2004), 461-468.

[15] PARK, D.-KIM, Y. H.-LEE, J. K. : Synthesis of Carbon Nanotubes on Metallic Substrates by a Sequential Combination of PECVD and Thermal CVD, Carbon 41 No. 5 (2003), 1025-1029.

[16] BONARD, J. M.-STÖCKLI, T.-NOURY, O.-CHÂTELAIN, A. : Field Emission from Cylindrical Carbon Nanotube Cathodes: Possibilities for Luminescent Tubes, Appl Phys Lett 78 No. 18 (2001), 2775-2777.

[17] JANÍK, J.-DANIŠ, T.-REDHAMMER, R.-ŠATKA, A.ČAPLOVIČOVÁ, M.: Morphology and Electron Field Emission from Carbon Nanotubes Prepared by Alcohol Catalytic Chemical Vapour Deposition, Acta Phys Slov 54 No. 3 (2004), 285-289.

[18] CAPLOVICOVA, M.-DANIS, T.-BUC, D.-CAPLOVIC, L.-JANIK, J-BELLO, I. : An Alternative Approach to Carbon Nanotube Sample Preparation for TEM Investigation, Ultramicroscopy 107 No. 8 (2007), 692-697.

[19] ZHOU, D.-CHOW, L. : Complex Structure of Carbon Nanotubes and their Implications for Formation Mechanism, J Appl Phys 93 No. 12 (2003), 9972-9976.

[20] LU, Y.-ZHU, Z.-SU, D.-WANG, D.-LIU, Z.-SCHLÖGL, R.: Formation of Bamboo-Shape Carbon Nanotubes by Controlled Rapid Decomposition of Picric Acid, Carbon 42 (2004), 3199-3207.

[21] ERMAKOVA, M. A.-ERMAKOV, D. Y.-CHUVILIN, A. L.-KUVSHINOV, G. G. : Decomposition of Methane over Iron Catalysts at the Range of Moderate Temperatures: The Influence of Structure of the Catalytic Systems and the Reaction Conditions on the Yield of Carbon and Morphology of Carbon Filaments, Journal of Catalysis 201 (2001), 183-197.

[22] GOLBERG, D.-Mitome, M.-MÜLLER, C.-TANG, C.LEONHARDT, A.-BANDO, Y.: Atomic Structures of IronBased Single-Crystalline Nanowires Crystallized Inside MultiWalled Carbon Nanotubes as Revealed by Analytical Electron Microscopy, Acta Materialia 54 No. 9 (2006), 2567-2576.

[23] KIM, H.-SIGMUND, W. : Iron Nanoparticles in Carbon Nanotubes at Various Temperatures, Journal of Crystal Growth 276 (2005), 594-605.
24] FENG, S. Q.-YU, D. P.-ZHANG, H. Z.-BAI, Z. G.-DING, Y.: The Growth Mechanism of Silicon Nanowires and their Quantum Confinement Effect, Journal of Crystal Growth 209 (2000), 513-517.

[25] TAKENAKA, S.-SERIZAWA, M.-OTSUKA, K. : Formation of Filamentous Carbons over Supported Fe Catalysts through Methane Decomposition, Journal of Catalysis 222 (2004), 520-531.

Received 12 April 2010

Mária Čaplovičová (Ing, CSc) was born in 1957 in Lozorno, Slovakia. She worked in the field of physical metallurgy and experimental methods of material analysis. The main part of research work was associated with the study of microstructure and properties of ferromagnetic materials. Present time she is interested in the study of nanomaterials using high resolution electron microscopy, electron diffraction and x-ray microanalysis.

L'ubomír Čaplovič (Ing, PhD) was born in 1955 (Senica). He is an associate professor of materials science and the head of the Laboratory of Structural Analysis at Institute of Materials Science, Faculty of Materials Science and Technology at Slovak University of Technology in Trnava, Slovak Republic. He has worked in the field of X-ray diffraction, light and electron microscopy, electron spectroscopy and microanalysis.

Dalibor Búc (Ing, CSc) was born in Dolný Kubín, Slovakia, in 1948. He graduated in solid state physics and received his $\mathrm{CSc}(\mathrm{PhD})$ in electronics and vacuum technology, both from the Slovak Technical University, in 1971 and 1980, respectively. Since 1981 he has worked as a scientist in the field of thin film technology and plasma processing (reactive magnetron sputtering, ion plating, ion beam sputtering) at the Department of Microelectronics FEI STU. He is a member of the Slovak Vacuum Society.

Peter Vinduška (Ing) was born in 1979 (Šala, Slovakia). He graduated (2005) from the Faculty of Electrical Engineering and Information Technology, Slovak University of Technology in Bratislava in microelectronics branch. Now he is the $\mathrm{PhD}$ student at FEI STU Bratislava. His research activities are the oriented growth of carbon nanotubes and use them as emitters of electrons.

Ján Janík (Assoc Prof, Ing, CSc) was born in Handlová in 1946. He received his Ing (MSc) degree in solid state physics, in 1970 and the CSc (PhD) in applied physics, in 1981, both form the Slovak University of Technology, Bratislava. Since 1992 he has been Associate Professor in Electronics (thesis: The Methodics of Ionooptical Elements and Systems Computation) at the Departmnet of Microelectronics of Slovak University of Technology. He tought different subjects as vacuum physics and technology, optoelectronics, microwave technology, electrical instrumentation, electron and ion technology, electronic and microelectronic elements, and microelectronic materials technology. In research he is oriented to ion beam optics and plasma technology. 